BMJ Paediatrics Open

\title{
Age, sex and ethnic differentials in the prevalence and control of epilepsy among Sri Lankan children: a population-based study
}

\author{
Jithangi Wanigasinghe, ${ }^{\oplus 1}$ Carukshi Arambepola, ${ }^{2}$ Roshini Murugupillai, ${ }^{3}$ \\ Thashi Chang ${ }^{4}$
}

To cite: Wanigasinghe $\mathrm{J}$, Arambepola C, Murugupillai $\mathrm{R}$, et al. Age, sex and ethnic differentials in the prevalence and control of epilepsy among Sri Lankan children: a population-based study. BMJ Paediatrics Open 2019;3:e000430. doi:10.1136/ bmjpo-2018-000430

Received 2 January 2019 Revised 3 April 2019 Accepted 11 April 2019
Check for updates

(C) Author(s) (or their employer(s)) 2019. Re-use permitted under CC BY-NC. No commercial re-use. See rights and permissions. Published by BMJ.

${ }^{1}$ Department of Paediatrics, Faculty of Medicine, University of Colombo, Colombo, Sri Lanka ${ }^{2}$ Department of Community Medicine, Faculty of Medicine, University of Colombo, Colombo Sri Lanka

${ }^{3}$ Department of Clinical

Sciences, Faculty of Health-Care Sciences, Eastern University, Sri Lanka, Batticaloa, Sri Lanka

${ }^{4}$ Department of Clinical Medicine, Faculty of Medicine, University of Colombo, Colombo, Sri Lanka

Correspondence to Dr Jithangi Wanigasinghe; jithangi@pdt.cmb.ac.lk

\section{ABSTRACT}

Objective To estimate the prevalence of childhood epilepsy in Sri Lanka by different age groups $(0-5,6-10$ and 11-16 years), sex and ethnicity, and to describe the types and outcomes of epilepsy.

Design and patients A population-based, crosssectional study was conducted in the district considered to be ethnically most balanced in Sri Lanka. A door-todoor survey was performed in the $0-5$ year age group (60 geographically defined areas as clusters; 19 children per cluster), and a school-based survey in the 6-16 year age group (150 classes as clusters; 25 children per cluster). The screened children with epilepsy were reviewed individually for confirmation of the diagnosis of epilepsy, typing of the underlying epilepsy syndrome and assessment of control. The same group of children were re-evaluated 1 year later to reconfirm the syndromic diagnosis and to assess the stability of control of epilepsy. Results The overall prevalence of childhood epilepsy was 5.7 per 10000 children aged $0-16$ years $(95 \% \mathrm{Cl}$ : 38 to 87 ). It was higher with younger ages (73.4 per 10000 children aged 0-5 years; 55.1 per 10000 children aged 6-10 years and 50.4 per 10000 children aged 11-16 years). A male dominance was noted in both age groups. In each age group, the prevalence was highest in children of Sinhalese ethnicity. Symptomatic focal epilepsy was the single most common group of epilepsy in both age groups. Majority of children remained well controlled on medications.

Conclusion The findings indicate a relatively high burden of epilepsy among children in Sri Lanka, however, these were comparable to the burden of disease reported from other countries in the region.

\section{INTRODUCTION}

Epilepsy is one of the most common chronic neurological diseases in children. Across all ages, it is the second most disabling disease as measured by years lived with disabilities. ${ }^{1}$ It is reported to affect $0.5 \%-1.0 \%$ of all children in general. ${ }^{2}$ Nevertheless, the variability in the precision of diagnosis of epilepsy raises concerns over the validity of these data. There is also variability depending on the setting of the studies. The reported epilepsy burden is low from high-income countries (HICs) ${ }^{2-6}$ Furthermore, recent literature from these settings reports declining prevalence rates of both adult and childhood epilepsy. ${ }^{7}$ Contrary to this, resource-poor settings, which harbour more than $80 \%$ of the epilepsy burden worldwide, report relatively higher prevalence rates. ${ }^{8}$ In particular, Asia contributes the largest proportion to this prevalence. This contribution is attributable to higher rates of perinatal injury, head trauma and central nervous system (CNS) infections including regional parasitic infections like neurocysticercosis. ${ }^{9}$ Recent literature has reported significantly varying prevalences within different regions in Asia. ${ }^{10}$ These differences need to be interpreted in the context of adopted methodology as well as cultural, social and economic factors that influence disease-reporting practices in these settings. ${ }^{9}$ Despite the overall high prevalence in Asia, reports of childhood epilepsy from this region is limited.

Sri Lanka is an island of $65610 \mathrm{~km}^{2}$ situated south of the Indian subcontinent between northern latitudes $5^{0}$ to $10^{0}$ with a population of approximately 22 million and a state healthcare system that is free to all of its citizens. However, not all people with epilepsy present to state hospitals because of not recognising the disease, access to private healthcare or reliance on alternative, indigenous healthcare providers. Thus, hospital-based data often underestimate the true burden of disease. Population-based epilepsy prevalence data in Sri Lanka is limited to a single study done in an adult population. ${ }^{11}$ Hence, the true magnitude of epilepsy among Sri Lankan children aged $0-16$ years remains unknown.

Understanding the true burden of childhood epilepsy is of paramount importance for financial estimations, resource distribution and projections for improving services for 
them. This is the first population-based study performed to estimate prevalence of childhood epilepsy in Sri Lanka (performed in 0-16 year age group in three different age categories: $0-5,6-10$ and $11-16$ years) and to describe the control of epilepsy in these children.

\section{METHODS}

Of the 25 districts in Sri Lanka, a population-based cross-sectional study was conducted in the district of Ampara, which comprises a land area of $4415 \mathrm{~km}^{2}$. This selection was based on its most balanced ethnic distribution where all three main ethnic groups (Sinhala, Tamil and Muslim) are nearly equally represented. This is a predominantly rural, agricultural district engaged in paddy cultivation and rice milling where the ethnic groups live in harmony.

The study population consisted of 4890 children aged $0-16$ years whose parents had been residing in the respective district for a minimum period of 6 months by the date of commencement of study and able to provide reliable clinical data from parental history and medical records. Parents not living with the child during most period of his/her life, with known psychiatric and mental illnesses were excluded. The sample size was calculated using the formula for estimating the prevalence of a disease. ${ }^{12}$ The sample initially calculated was 1432 to detect an expected prevalence of $0.6 \%$ of epilepsy among children aged $0-16$ years (in the absence of a previous study conducted among children aged $0-16$ years, or separately in $0-5$, 6-10 and 11-16 age groups in Sri Lanka/Asia, p was based on the prevalence reported from a study among Asian children aged $0-18$ years), ${ }^{13}$ with a precision of $0.004(\mathrm{~d})$ and a level of confidence of $1.96(\mathrm{Z})$. This sample was recruited proportionate to the following age-specific population data of Sri Lanka ${ }^{14}: 0-5$ years (26.7\% of the sample comprising infants, young children and preschoolers; $\mathrm{n}=382)$ and $6-16$ years $(73.3 \%$ of the sample comprising grades 1-11 schoolgoing children; $\mathrm{n}=1050$ ).

In the $0-5$ year age group, a community-based sample of 1140 was obtained in clusters of 19 children per public health midwife (PHM) area, from each of the $60 \mathrm{PHM}$ areas in the district. PHM area is the smallest administrative unit in the national healthcare system. This final sample was determined by multiplying the initial sample of 382 by 2.8 (design effect calculated for a cluster size of 19 children and rho value of 0.1 ) to minimise cluster effect and 5\% non-response. From each PHM area, a cluster of 19 children was selected systematically using the Birth \& Immunisation registers maintained and routinely updated by the respective area PHM.

In the 6-16 year age group, a school-based sample of 3750 (1500 from grades 1 to 5 and 2250 from grades 6 to 11 , so as to represent, respectively, the $6-10$ and $11-16$ year age groups proportionate to the age-specific population data in Sri Lanka) ${ }^{14}$ was obtained in clusters of 25 children per class, from 150 classes (60 classes from grades 1 to 5 and 90 classes from grades 6 to 11). This final sample was determined by multiplying the initial sample of 1050 by design effect of 3.4 (calculated for a cluster size of 25 children and rho value of 0.1 ) and $5 \%$ non-response. To obtain this sample, a total of 15 schools (5 schools from each stratum classified as 'Sinhala', 'Tamil' and 'Muslim' schools) were selected randomly. From each selected school, 10 classes per school (4 classes from grades 1 to 5 and 6 classes from grades 6 to 11) were selected randomly. From each selected class, a cluster of 25 children belonging to the main ethnic group of that school was selected systematically using the student attendance register. School enrolment is a mandatory requirement of the country, where parents are legally bound to ensure school enrolment after completion of 5 years of age. Compulsory schooling up to General Certificate of Education Ordinary Level examination (at 16 years) is also ensured through the free education system.

Data collection was done in two stages: initial screening for epilepsy, followed by confirmation of their diagnosis. Parents of children aged $0-5$ years were visited at their homes, while the parents of school children were approached through class teacher by inviting them to participate in the study. The consenting parents of school children were administered a pretested questionnaire to screen for occurrence of any type of seizure. Two different questionnaires were used for the two groups of children. Each was developed using extracts from a validated assessment form developed by University of Melbourne for obtaining information pertaining to epilepsy. ${ }^{15}$ The questionnaires were translated into two main local languages, and assessed for validity by mothers of $0-16$ aged children (face validity) and a multidisciplinary panel of experts in fields of paediatric neurology and community medicine (content and consensual validity).

Once screening for epilepsy was completed, those screened as having even a single afebrile seizure from the two age groups were invited to participate in a clinic-based evaluation. At this review, a detailed analysis of epilepsy history, underlying epilepsy syndrome, response to therapy and current epilepsy control was performed by a paediatric neurologist during a one-to-one interview conducted at the regional hospital in the district which had facilities for confirmation of electroencephalographic findings. Diagnosis of epilepsy was based on recently published International League Against Epilepsy (ILAE) operational clinical definition of epilepsy of 2014. ${ }^{16}$ Active epilepsy was defined as those who have had at least one seizure during preceding 5 years of living with their epilepsy. A modified form of the ILAE classification of epilepsy control after epilepsy surgery was used to describe epilepsy control (table 1). ${ }^{17}$ In those with confirmed diagnosis, information about the epilepsy onset, seizure semiology, electroencephalographic and neuroimaging findings, records of anticonvulsant therapy received, response to therapy were reviewed and those with epilepsy were classified into four broad types according to the dichotomised epilepsy 
Table 1 Epilepsy outcome classification modified from the ILAE classification of outcome with respect to epileptic seizures following epilepsy surgery

\begin{tabular}{ll}
\hline $\begin{array}{l}\text { Outcome } \\
\text { description } \\
\text { classification }\end{array}$ & Description \\
\hline 1 & Completely seizure free; no auras \\
\hline 2 & Only auras; no other seizures \\
\hline 3 & One to three seizure days per year; \pm auras \\
\hline 4 & Four to 12 seizure days per year; +aura \\
\hline 5 & Daily seizures; \pm auras \\
\hline 6 & $\begin{array}{l}\text { More than } 100 \% \text { increase of baseline } \\
\text { seizure days; } \pm \text { auras }\end{array}$ \\
\hline
\end{tabular}

ILAE, International League Against Epilepsy.

classification of $1989 .{ }^{18}$ All the clinical information was reviewed independently by a second neurologist to confirm the broad syndromic diagnosis. The underlying broad epilepsy syndrome was established as idiopathic focal or generalised or symptomatic focal or generalised by consensus decision. All children with confirmed diagnosis of epilepsy were reviewed 1 year later to reconfirm the syndromic diagnosis and to describe the epilepsy control. Ethics clearance was obtained from Ethics Review Committee, Faculty of Medicine, University of Colombo, while permission was obtained from the relevant education ministry officials.

Patient and public involvement was incorporated for the process of development of the two questionnaires, and parents' input was used for the assessment of face validation of the questionnaires developed.

\section{RESULTS}

The sample included 4330 children. Majority consisted of males $(\mathrm{n}=2237 ; 51.7 \%)$. Age groups included 1090 children in $0-5$ age group (25.2\%), 1453 in 6-10 age group (33.5\%) and 1787 in 11-16 age group (41.3\%). An adequate number of children were present in each ethnic group (Sinhala 1382, Tamil 1502 and Muslims 1446).

Total number of children aged $0-5$ years screened for epilepsy was 1090 (95.6\% response rate). This included 525 males and 565 females (1:1.1). Of them, the total number screened as having epilepsy was 14. Among them, eight children fulfilled the diagnostic criteria and were confirmed as having definite epilepsy, giving an overall prevalence rate of 73 per 10000 children in $0-5$ age group (95\% CI: 37 to 144 ).

In the school-based survey, total number screened for epilepsy was 3240 ( $86.4 \%$ response rate). It included 1712 males and 1528 females (1:1.12). Of them, 36 indicated at least one episode of abnormal event; however, only 25 fulfilled criteria to screen for epilepsy. Of them, $23(92 \%)$ were present with their parents for a detailed evaluation, while 2 children did not participate as their

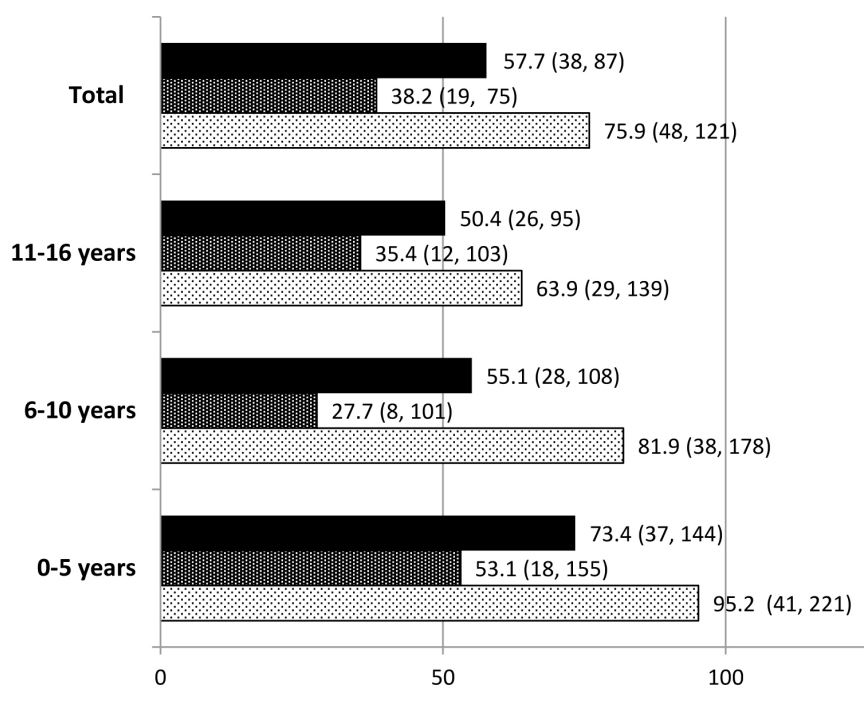

Epilepsy Prevalence per 10,000 child population

- Total 目Female 0 Male

Figure 1 Age-specific and sex-specific prevalence of epilepsy (95\% Cls) among children aged 0-16 years in the district of Ampara, Sri Lanka.

parents refused consent. Of the consenting 23, 17 children were confirmed as having definite epilepsy, giving an overall prevalence rate of 52.5 per 10000 children aged $6-16$ years (95\% CI: 33 to 84 ). On further analysis, the prevalence was 55.1 per 10000 children aged $6-10$ years (95\% CI: 28 to 108 ) and 50.4 per 10000 children aged 11-16 years (95\% CI: 26 to 95 ).

Age-specific and sex-specific prevalence of epilepsy is shown in figure 1 . Highest prevalence was noted in $0-5$ age group in both males and females. Prevalence seemed to decrease with advancing age. Male predominance was seen in $0-5$ age group $(n=5 ; 62.5 \%)$ with $1.8: 1$ ratio between males (95.2 per 10000 males) and females (53.1 per 10000 females) as well as in 6-16 age group $(n=12$; $70.6 \%$ ) with 2:1 ratio between males (70.1 per 10000 males) and females (32.7 per 10000 females).

Age-specific and ethnicity-specific prevalence of epilepsy is shown in figure 2. In each age group, the prevalence was highest in Sinhala children and lowest in Tamil children.

Among the children aged 0-5 years, febrile seizure was the single most common factor for misdiagnosing epilepsy. Of the eight with definite epilepsy, only six presented for detailed evaluation. The most common underlying broad syndromic group was symptomatic focal epilepsy $(66 \%)$. One of them initially suffered from symptomatic generalised epilepsy (West syndrome) which had resolved and was suffering from symptomatic focal epilepsy at the time of evaluation. The others had symptomatic generalised epilepsy manifesting as West syndrome (17\%) and Lennox-Gastaut syndrome (17\%). All six had 'active' epilepsy but their control was variable (class 2 in two, class 4 and 5 in four). Five were on regular 


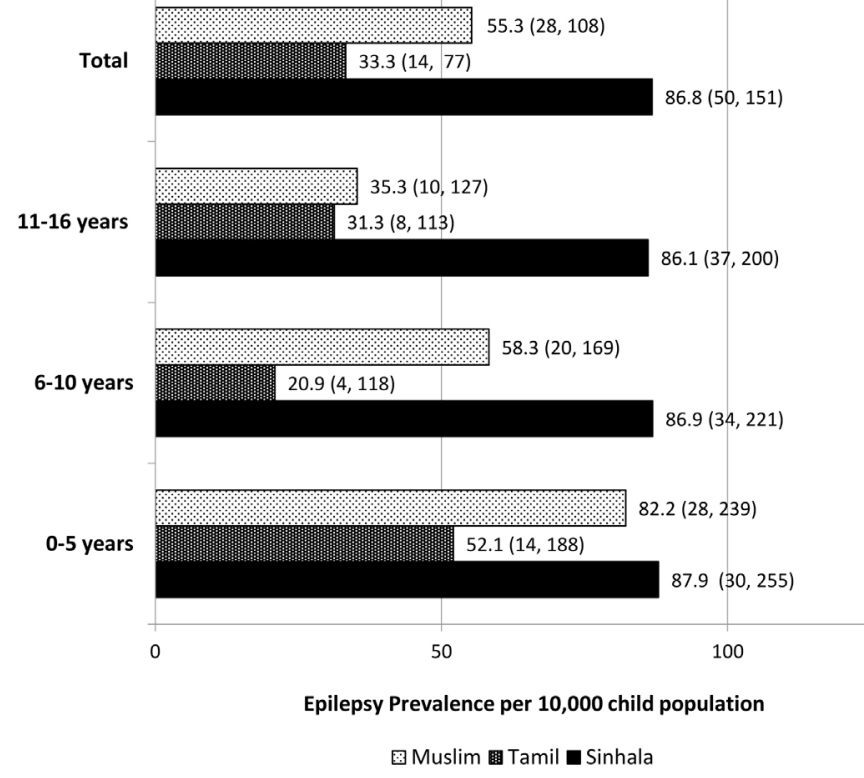

Figure 2 Ethnic-specific prevalence of epilepsy (95\% Cls) among children aged 0-16 years in the district of Ampara, Sri Lanka.

antiepileptic medication, and one used benzodiazepine prophylaxis during febrile illness only.

Epilepsy types in the school age group identified symptomatic focal epilepsy as the predominant type (70\%). Two experienced rolandic epilepsy (12\%); epilepsy type was undifferentiated in two (12\%), and one had symptomatic generalised epilepsy (6\%). In this group all but one was identified to be in active epilepsy based on the definition used. However, within this group there were five (of whom four were off medications) who enjoyed seizure freedom for $>3$ years. Epilepsy control described using the modified ILAE epilepsy surgery outcome scale, showed variable control. Good control of class 1 and 2 levels was seen in 11, whereas poor control with class 4 and 5 levels was seen in 6 .

Epilepsy control in the overall group was good with $13(52 \%)$ enjoying good control (class 1 or 2). In the 23 patients evaluated, this was without any antiepileptic medication in 3 , using monotherapy in 8 and polytherapy in 12. Carbamazepine and sodium valproate were the most frequently prescribed. Re-evaluation of both groups of children was performed in the same setting 1 year later. Of the initial 23 children reviewed, only 17 children presented for this assessment. The epilepsy control remained unchanged in all those previously in class 5, but improvement from class 4 to class 2 was seen in two children. There were none with worsening frequency.

\section{DISCUSSION}

The overall prevalence of epilepsy among Sri Lankan children was 57.7 per 10000 children aged $0-16$ years, increasing with age. It was predominant with male gender and Sinhala ethnicity. Symptomatic focal epilepsy appears to be the the most common single group of epilepsy syndromes $(68 \%)$. The epilepsy control varied from remission to experiencing frequent seizures. In spite of the low income setting, majority of children were well-controlled and their epilepsy remained stable over the next 1 year.

Estimation of the burden of epilepsy in a country is heavily influenced by the study methodology. ${ }^{19} 20$ This includes the definition of epilepsy used, validity of data collected and accurate diagnosis of epilepsy, particularly since many non-epileptic paroxysmal conditions occur in childhood. ${ }^{21}$ Evolution of definition of epilepsy is also likely to contribute to the differing rates in more recent studies compared with those reported previously. Most studies have not performed age-adjusted estimations. Although ethnic distribution of the sample was biased toward the minor ethnicities, it did not affect the study findings, as the prevalence of epilepsy in this study was stratified by age, sex and ethnicities. As expected, the participation and reported rates are much higher in door-to door surveys than from record-based reviews or administrative database research. ${ }^{10}$ In spite of these limitations, age-specific, sex-specfic and ethnic-specific estimations of burden of epilepsy remain important for projection and planning of health services and prioritisation of resources within a country. Our study is the first to estimate the disease burden of epilepsy among Sri Lankan children. Evaluation of children face-face by content experts added reliability to the estimations.

Burden of epilepsy in general is higher in low-income countries (LICs) in comparison to that in $\mathrm{HICs}^{2-4}$. This is due to high incidences of some of the symptomatic causes of epilepsy, such as perinatal injuries and CNS infections in LICs. The rate of consanguineous marriages is also higher in these countries. The overall interpretation of our findings agrees with above per capita-based observation. When comparing with regional prevalence rates reported from other Asian countries, our estimates were higher than that reported in India ${ }^{22}$ and China. ${ }^{23}$ However, it was lower than the rates reported in Pakistan ${ }^{24}$ and Saudi Arabia. ${ }^{25}{ }^{26}$ It is interesting to note that, in a review that considered studies using the same definition with adjustment for age, the lowest rates of epilepsy were found to be reported from Asia, followed by the USA and Europe. ${ }^{10}$ The highest rates were reported for Latin America ${ }^{27}$ and Africa. ${ }^{10}$ One reason for these low rates in the Asian continent may be related to under-reporting due to high rates of stigmatisation in this region. This under-reporting is reflected to some extent in our findings as well. This is more in certain ethnic groups than the other. Furthermore, in a country like India, the reported rates for children vary between those in HICs $(3.4 / 1000$ from Kashmir) and those in other regional LICs $(7.5 / 1000$ from Uttarakhand) ${ }^{29}$ These differences are attributed to differences in standard of healthcare provision within different states in India. ${ }^{29}$ A comparison of prevalence of epilepsy in different regions against findings from our study is showcased in figure 3 . 


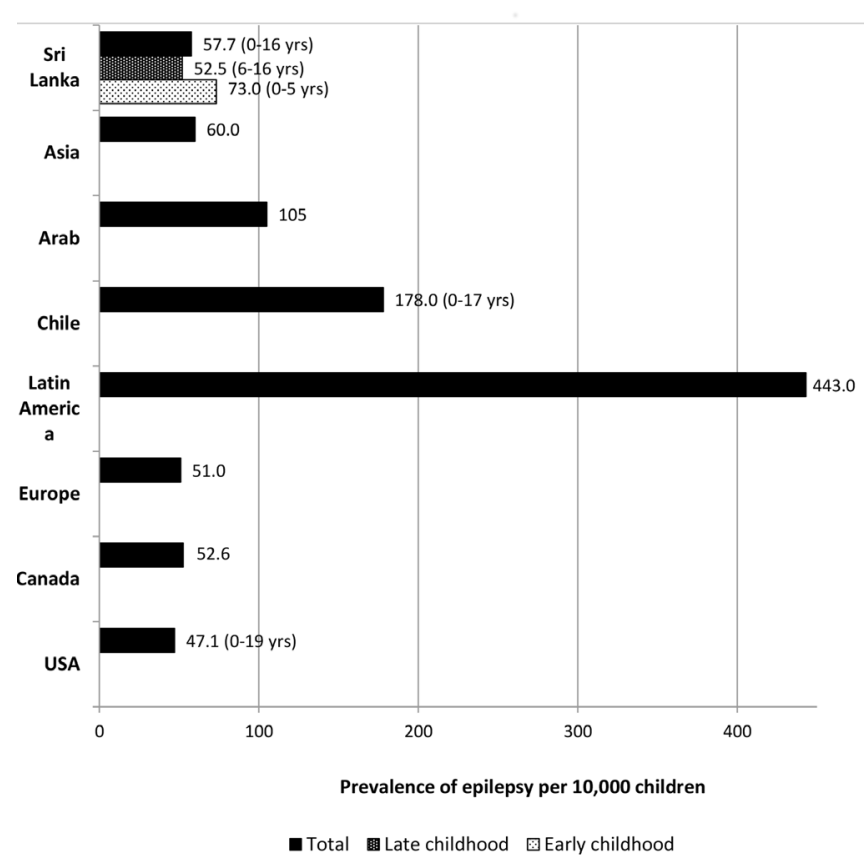

Figure 3 Comparison of the age-adjusted crude prevalence of epilepsy in Sri Lankan children aged 0-16 years with other countries.Prevalence of epilepsy (age group wherever specified is given within brackets) in each country is based on the following references: Sri Lanka (current study), Arab, ${ }^{25}$ Asia, ${ }^{12}$ Chile, ${ }^{27}$ Latin America, ${ }^{26}$ Europe, ${ }^{6}$ Canada, ${ }^{31}$ and USA. ${ }^{32}$

Most studies in the past concentrated only on the overall estimates of incidence or prevalence of epilepsy in a region. Over the years, more specific data related to age-specific and gender-specific estimates of epilepsies, classification on type of epilepsies, aetiology-based epilepsies and evaluation-based socioeconomic strata have been ascertained in population-based estimations of epilepsy. ${ }^{10}$ Similar to our study, globally a higher incidence of epilepsy is reported in the males. ${ }^{30}$ We looked at ethnicity, considering the higher rates of interfamily marriages in some ethnic groups.

Highest incidence of epilepsy during a lifetime is reported during the first year of life. In a recent Norwegian study, this was estimated to be 144 per 100000 (CI 122 to 168 ) person-years. ${ }^{2}$ This is in comparison to 61 in the 1-4 year group and 54 in the 5-10 year age group in the same study per 100000 . The prevalence rate was lower in the older age group. Our study looked at some age-specific and gender-specific prevalence patterns as well as types of epilepsies and epilepsy control. A higher prevalence rate in the younger age group, similar to above, was seen in our study.

Considering the likelihood of some childhood epilepsies to achieve remission, evaluating the cumulative incidence of epilepsy as well as prevalence of active epilepsy may be more reliable indicators for accurate estimation of disease burden of childhood epilepsy. In this study, we reported an overall good control of epilepsy in spite of many considered to be in active epilepsy. Considering the smaller number of patients, limiting the estimate of active epilepsy to only past
2 years instead of 5 years would have yielded a better estimate of the control of epilepsy.

\section{Limitations}

Although 'childhood' is defined as the period from birth to completion of 18 years of life, the upper limit considered in this study was 16 years. This was due to high school drop-out rate experienced in Sri Lanka after the age of 16 . However, in the age group we selected (6-16 years), we postulated that the random sample selected to be a reasonable representative sample of school children aged $6-16$ as the rate of school entry at 5 years of age is nearly $100 \%$ in the country. However, in the school-based survey there may have been under-reporting of disease condition due to myriad of social and cultural factors that stigmatise children with epilepsy, and physical disability owing to the poor control that may prevent the most severely affected children with epilepsy avoiding school, leading to school absenteeism. In our study, the sample size was calculated for $0-16$ age group, without considering the variation in the prevalence of epilepsy within it. However, given the large sample recruited within each age group, we assume that the study was adequately powered to estimate the prevalence of epilepsy stratified by the three age groups. The lowest prevalence of epilepsy was reported among the Muslim ethnic group. However, considering the immunisation failure rate and the incidence of consanguineous marriages, one would expect a higher rate of epilepsy among this group. The above findings, particularly in the schoolgoing age groups (6-10 and 11-15), may indicate an under-reporting due to stigma feared by this ethnic group.

\section{CONCLUSIONS}

This is the first population-based study to estimate the disease burden of epilepsy among children in Sri Lanka and is likely to be useful in planning and delivery of efficient epilepsy prevention, treatment and rehabilitation

\section{What is known about the subject?}

The burden of epilepsy is greater in countries in low-income settings in comparison to those in the high-income regions.

- Data related to incidence and prevalence of childhood epilepsy are limited even in high-income settings but more so from low-income countries.

- The prevalence of epilepsy varies with age and is highest in the early years of life.

\section{What this study adds?}

The prevalence of epilepsy in the Sri Lankan children studied was 5.7 per 10000 .

- Describes that in spite of the low-income status and geographical setting of our country, the control of childhood epilepsy was good in the majority.

- The most widely used antiepileptic drugs were carbamazepine and sodium valproate. 
services nationally, regionally and globally. It also adds to the limited data on disease estimations in the region. However, this data may not represent the country as a whole due to regional differences in socioeconomic status. Future studies should include participants from urban and rural communities from different parts of the country to improve external validity.

Acknowledgements We acknowledge the funding received from the World Bank.

Contributors JW was responsible for overall conceptualisation, conduct of the study and obtaining the research funding in the capacity of the principal investigator. She was also responsible for evaluating all the screened patients with epilepsy at the local hospital. She was responsible for most of the writing of the article. CA was the epidemiologist who did all sample size calculations and the final data analysis and interpretation. She made a significant contribution toward compilation of the article. RM was involved in the data collection, compilation and data entry. Contributed toward modifications and finalising the article. TC was responsible for independent evaluation of the diagnosis of epilepsy in the population. He contributed significantly toward the improvement of the final draft of the paper.

Funding We confirm that we have read the journal's position on issues involved in ethical publication and affirm that this report is consistent with those guidelines. This study received funding from the World Bank as part of the grant for better Higher Education in the Twentieth Century (HETC) (2012).

Competing interests None declared.

Patient consent for publication Not required.

Provenance and peer review Not commissioned; externally peer reviewed.

Data availability statement Data are available on reasonable request.

Open access This is an open access article distributed in accordance with the Creative Commons Attribution Non Commercial (CC BY-NC 4.0) license, which permits others to distribute, remix, adapt, build upon this work non-commercially, and license their derivative works on different terms, provided the original work is properly cited, appropriate credit is given, any changes made indicated, and the use is non-commercial. See: http://creativecommons.org/licenses/by-nc/4.0/.

\section{REFERENCES}

1. GBD 2017 DALYs and HALE Collaborators. Global, regional, and national disability-adjusted life-years (DALYs) for 359 diseases and injuries and healthy life expectancy (HALE) for 195 countries and territories, 1990-2017: a systematic analysis for the global burden of Disease Study 2017. Lancet 2018;392:1859-922.

2. Aaberg KM, Gunnes N, Bakken IJ, et al. Incidence and prevalence of childhood epilepsy: a nationwide cohort study. Pediatrics 2017;139. doi:10.1542/peds.2016-3908

3. Hauser WA, Annegers JF, Kurland LT. Incidence of epilepsy and unprovoked seizures in Rochester, Minnesota: 1935-1984. Epilepsia 1993;34:453-8.

4. Camfield P, Camfield C, Incidence Camfield C:. Incidence, prevalence and aetiology of seizures and epilepsy in children. Epileptic Disord 2015;17:117-23.

5. Meeraus WH, Petersen I, Chin RF, et al. Childhood epilepsy recorded in primary care in the UK. Arch Dis Child 2013;98:195-202.

6. Forsgren L, Beghi E, Oun A, et al. The epidemiology of epilepsy in Europe - a systematic review. Eur J Neurol 2005;12:245-53.

7. Saarinen MM, Sillanpää M, Schmidt D, et al. Long-term changes in the incidence of childhood epilepsy. A population study from Finland. Epilepsy Behav 2016;58:81-5.
8. Ngugi AK, Bottomley C, Kleinschmidt I, et al. Estimation of the burden of active and life-time epilepsy: a meta-analytic approach. Epilepsia 2010;51:883-90.

9. Espinosa-Jovel C, Toledano R, Aledo-Serrano Ángel, et al. Epidemiological profile of epilepsy in low income populations. Seizure 2018;56:67-72.

10. Banerjee PN, Filippi D, Allen Hauser W. The descriptive epidemiology of epilepsy-a review. Epilepsy Res 2009;85:31-45.

11. Senanayake N. Epilepsy control in a developing country--the challenge of tomorrow. Ceylon Med J 1987;32:181-99.

12. Lwanga SK, Lemeshow S. Sample size determination in health studies: a praticle mannual who, 1991.

13. Mac TL, Tran D-S, Quet F, et al. Epidemiology, aetiology, and clinical management of epilepsy in Asia: a systematic review. Lancet Neurol 2007;6:533-43.

14. DCS: Census Population \& Housing 2011/2012. Colombo: department of census and statistics, 2012.

15. Reutens DC, Howell RA, Gebert KE, et al. Validation of a questionnaire for clinical seizure diagnosis. Epilepsia 1992;33:1065-71.

16. Fisher RS, Acevedo C, Arzimanoglou A, et al. ILAE official report: a practical clinical definition of epilepsy. Epilepsia 2014;55:475-82.

17. Wieser HG, Blume WT, Fish D, et al. Commission on neurosurgery of the International League against E: ILAE Commission report. Proposal for a new classification of outcome with respect to epileptic seizures following epilepsy surgery. Epilepsia 2001:42:282-6.

18. Proposal for revised classification of Epilepsies and epileptic syndromes. Commission on classification and terminology of the International League against epilepsy. Epilepsia 1989;30:389-99.

19. Tan M, Wilson I, Braganza V, et al. Development and validation of an epidemiologic case definition of epilepsy for use with routinely collected Australian health data. Epilepsy Behav 2015;51:65-72.

20. Reid AY, St Germaine-Smith C, Liu M, et al. Development and validation of a case definition for epilepsy for use with administrative health data. Epilepsy Res 2012;102:173-9.

21. Bye AM, Kok DJ, Ferenschild FT, et al. Paroxysmal non-epileptic events in children: a retrospective study over a period of 10 years. $J$ Paediatr Child Health 2000;36:244-8.

22. Radhakrishnan K, Pandian JD, Santhoshkumar T, et al. Prevalence, knowledge, attitude, and practice of epilepsy in Kerala, South India. Epilepsia 2000;41:1027-35.

23. Li SC, Schoenberg BS, Wang CC, et al. Epidemiology of epilepsy in urban areas of the People's Republic of China. Epilepsia 1985;26:391-4.

24. Aziz H, Güvener A, Akhtar SW, et al. Comparative epidemiology of epilepsy in Pakistan and Turkey: population-based studies using identical protocols. Epilepsia 1997;38:716-22.

25. Al Rajeh S, Awada A, Bademosi O, et al. The prevalence of epilepsy and other seizure disorders in an Arab population: a communitybased study. Seizure 2001;10:410-4.

26. Benamer HTS, Grosset DG. A systematic review of the epidemiology of epilepsy in Arab countries. Epilepsia 2009;50:2301-4.

27. Burneo JG, Tellez-Zenteno J, Wiebe S. Understanding the burden of epilepsy in Latin America: a systematic review of its prevalence and incidence. Epilepsy Res 2005;66:63-74.

28. Lavados J, Germain L, Morales A, et al. A descriptive study of epilepsy in the District of El Salvador, Chile, 1984-1988. Acta Neurol Scand 1992;85:249-56.

29. Gadgil P, Udani V. Pediatric epilepsy: the Indian experience. J Pediatr Neurosci 2011;6(Suppl 1):S126-9.

30. Olafsson E, Ludvigsson P, Gudmundsson G, et al. Incidence of unprovoked seizures and epilepsy in Iceland and assessment of the epilepsy syndrome classification: a prospective study. Lancet Neurol 2005;4:627-34

31. Prasad AN, Sang X, Corbett BA, et al. Prevalence of childhood epilepsy in Canada. Can J Neurol Sci 2011;38:719-22.

32. Cowan LD, Bodensteiner JB, Leviton A, et al. Prevalence of the epilepsies in children and adolescents. Epilepsia 1989;30:94-106 